limited Z-band streaming, a feature related to severe contraction of individual myofibrils.

The association of malignant hyperpyrexia with central core disease is well established, ${ }^{7}$ so much so, that all patients with this condition, including the relatives, should be considered to be at risk from malignant hyperpyrexia unless in vitro contracture tests indicate otherwise.

The association with Duchenne's muscular dystrophy and other myopathies is less definite but it does lend support to the concept that the, as yet unidentified, malignant hyperpyrexia gene is probably located near to the other myopathy related genes.
We thank Mr A Strang, consultant neurosurgeon, for allowing this case to be reported, and the Medical Illustration Department, Manchester Medical School, for the histological photography.

1 Ellis FR, Halsall PJ. Malignant hyperpyrexia. $\mathrm{Br} J$ Hosp Med 1980;24:318-27.

2 Denborough MA, Lovell RRH. Anaesthetic deaths in a family. Lancet $1960 ; \mathrm{ii}: 45$.

3 Joseph MM, Shah K, Vilioen JF. Malignant hyperthermia associated with Isoflurane anesthesia. Anesth Analges associated with

4 Boheler J, Eger EI. Isoflurane and malignant hyperthermia. Anesth Analges 1982;61:712-13.

5 Harriman DGF. Malignant hyperthermia myopathy-a critical review. Br J Anaesth 1988;60:309-16.

6 Harriman DGF, Sumner DW, Ellis FR. Malignant hyperpyrexia myopathy. $Q J$ Med 1973;42:639-64.

7 Brownell AKW. Malignant hyperthermia: relationship to other diseases. Br J Anaesth 1988;60:303-8.

\title{
Dieulafoy's vascular malformation as a cause of large intestinal bleeding
}

\author{
D J Farrell, M K Bennett
}

\begin{abstract}
Four cases of Dieulafoy's vascular malformation of the caecum are reported. Three were associated with massive large bowel haemorrhage, one of which was fatal. The remaining case had a calibre persistent submucosal artery within the caecum that was found incidentally in a resection specimen.

This vascular malformation should be considered when dealing with specimens resected for massive lower gastrointestinal bleeding.
\end{abstract}

Dieulafoy's vascular malformation, also known as calibre persistent submucosal artery, is a rare but well known cause of upper gastrointestinal bleeding. ${ }^{1}$ It has been found almost exclusively in the stomach, although cases in the duodenum ${ }^{2}$ and jejunum ${ }^{3}$ have also been reported. Recently it has been recognised that it may occur in the colon and can cause massive bleeding. ${ }^{4}$ To date there have been six cases of large bowel haemorrhage from a Dieulafoy type ulcer. $^{4-7}$ We report four more cases.

\section{Case reports}

CASE 1

Department of Histopathology, Freeman Hospital, High Heaton, Newcastle upon Tyne NE7 7DN D J Farrel M K Bennett Correspondence to: Dr D J Farrell Accepted for publication 5 September 1991
A 77 year old man was admitted with severe continuous bleeding from the rectum and lower abdominal pain which he had had for six hours. He had previously undergone repair of a perforated gastric ulcer and was known to have polycythemia rubra vera. He was in circulatory shock and required transfusion of 8 units of blood over the following 10 hours. An emergency oesophago-gastro-duodenoscopic examination was normal. Because of continued bleeding, emergency superior mesenteric angiography was performed which showed arterial bleeding in the caecal tip. An emergency right hemicolectomy was therefore carried out. At surgery blood had filled the whole of the large bowel but there seemed to be none in the small bowel.

After inflation of the specimen with barium to show the vessels, macroscopic examination showed a small ulcer $0.2 \mathrm{~cm}$ in diameter inside the tip of the caecum. Microscopic examination of the caecal ulcer showed a thrombus covering a muscular artery of large diameter within the submucosa and extending into the mucosa which had ruptured into the lumen (fig 1). There was no evidence of arteritis. There was a localised inflammatory response in the immediately adjacent mucosa but the bowel was otherwise unremarkable. The appearances were identical with those of a Dieulafoy ulcer as described in the stomach. ${ }^{1}$

\section{CASE 2}

A 64 year old man with known alcoholic liver disease was admitted with anorexia, weight loss, increasing dyspnoea and melaena. On examination he had the stigmata of chronic liver disease. Because of repeated nose bleeds he required multiple transfusions but continued to be anaemic. He was also known to have oesophageal varices. He continued to pass large volumes of melaena with blood clots daily and had evidence of a chest infection. Despite supportive measures he died eight days after admission.

Post mortem examination showed a widespread, diffuse non-Hodgkin's lymphoma. Altered blood was present in the stomach and 
Figure 1 Thrombus covering an eroded large diameter muscular artery in the mucosa

(haematoxylin and eosin).

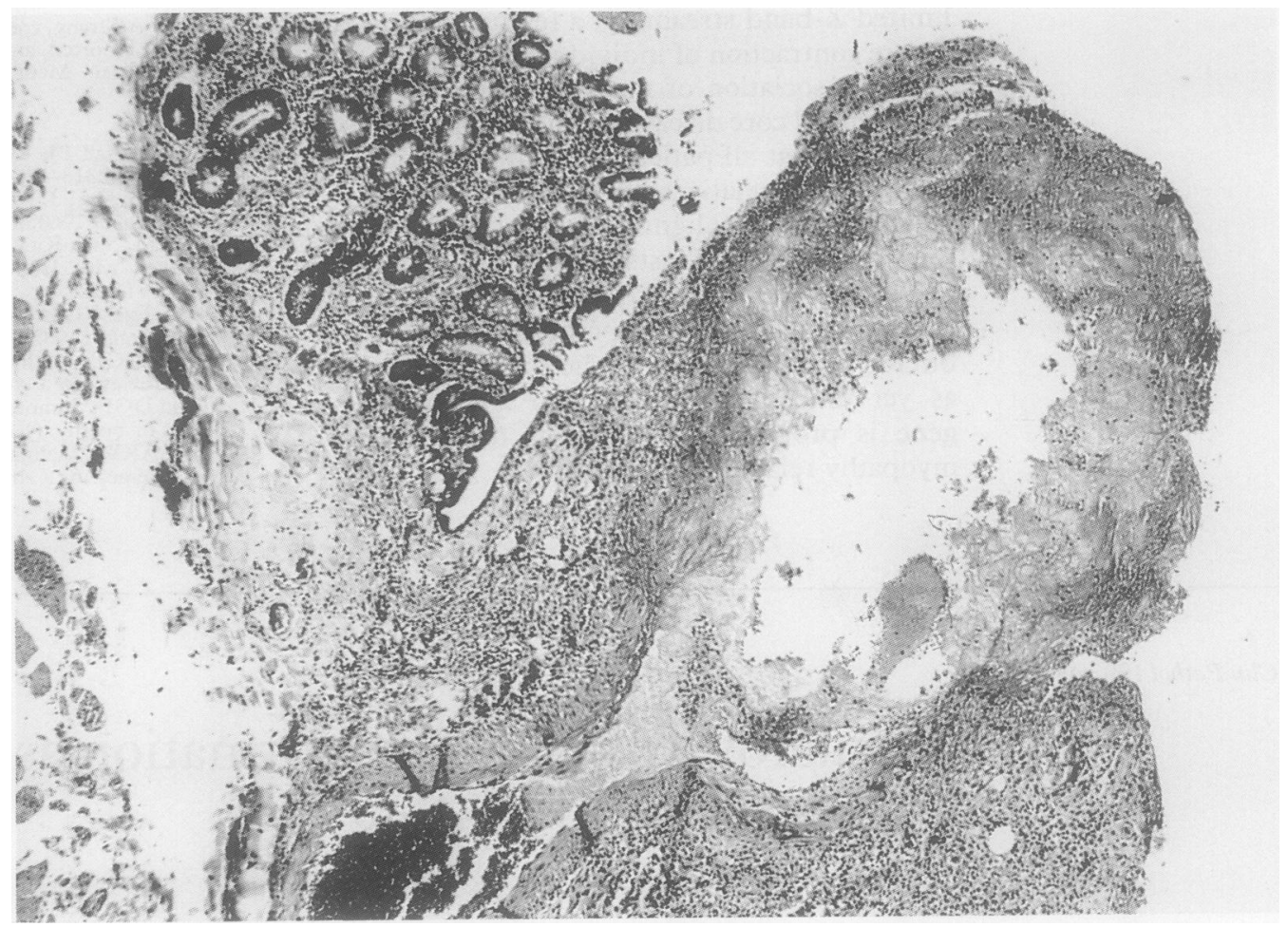

small bowel, and this was felt to be related to the episodes of nose bleeding and possible ruptured oesophageal varices. Blood was present in the large bowel and there was an ulcer $4 \times 1.5 \mathrm{~cm}$ in the caecum. Microscopic examination showed a localised erosion with extension into the upper submucosa. In the base of the erosion several thick walled muscular arteries were present in close proximity to the adjacent muscularis mucosae and looping towards the surface. These arteries showed eccentric intimal fibrosis and no evidence of arteritis. The appearances were similar to a Dieulafoy type ulcer.

\section{CASE 3}

An 80 year old woman with rheumatoid arthritis was admitted for control of knee pain and attention to a leg ulcer. During her admission she developed several episodes of bleeding from the rectum for which she was treated with repeated transfusions. The bleeding episodes continued, however, and she developed circulatory shock. Emergency superior mesenteric angiography showed that there was a bleeding point in the caecum and consequently an emergency limited right hemicolectomy was performed. At surgery the caecum was full of pus and there was blood in the distal small bowel and throughout the colon.

Macroscopic examination confirmed a large amount of fresh blood and blood clot within the caecum and ascending colon. Two linear ulcers were identified within the caecum measuring $3 \times 0.5 \mathrm{~cm}$ at the widest point. Microscopic examination showed a localised area of mucosal ulceration which extended into the superficial submucosa. In the base of the ulcer was a large diameter muscular artery looping towards the surface. An elastic stain showed fragmentation of the internal elastic lamina (fig 2). There was no evidence of arteritis and the adjacent bowel was unremarkable. The appearances were similar to a Dieulafoy type ulcer.

\section{CASE 4}

A 75 year old woman was admitted with a 10 day history of subacute large bowel obstruction. An emergency extended right hemicolectomy was performed for an obstructing carcinoma of the descending colon with gross distension of the caecum.

Microscopic examination confirmed a moderately differentiated large bowel adenocarcinoma (Dukes' B). Random blocks from the caecum showed a large, thick-walled muscular artery in the submucosa, without overlying mucosal ulceration. The artery showed subintimal fibrosis and had a large diameter vein accompanying it. The appearances were those of a calibre persistent submucosal artery.

\section{Discussion}

The histological features of a Dieulafoy ulcer have been well described, ${ }^{1}$ but the pathogenesis of the vascular malformation is disputed. It is not known whether it is congenital or an acquired anomaly, or merely a variation of normal. ${ }^{3}$ It is generally agreed that there is a large submucosal artery lying in close contact with the mucous membrane over a variable distance. It is thought that this is attached to the muscularis mucosae and that the calibre of the vessel is greatly oversized at that site. ${ }^{89}$ Massive bleeding can occur if erosion of the mucous membrane and arterial wall occurs.

The incidence of Dieulafoy's vascular mal- 
Figure 2 Fragmentation of the internal elastic lamina of a large diameter muscular artery beneath a localised erosion (elastic van Gieson).

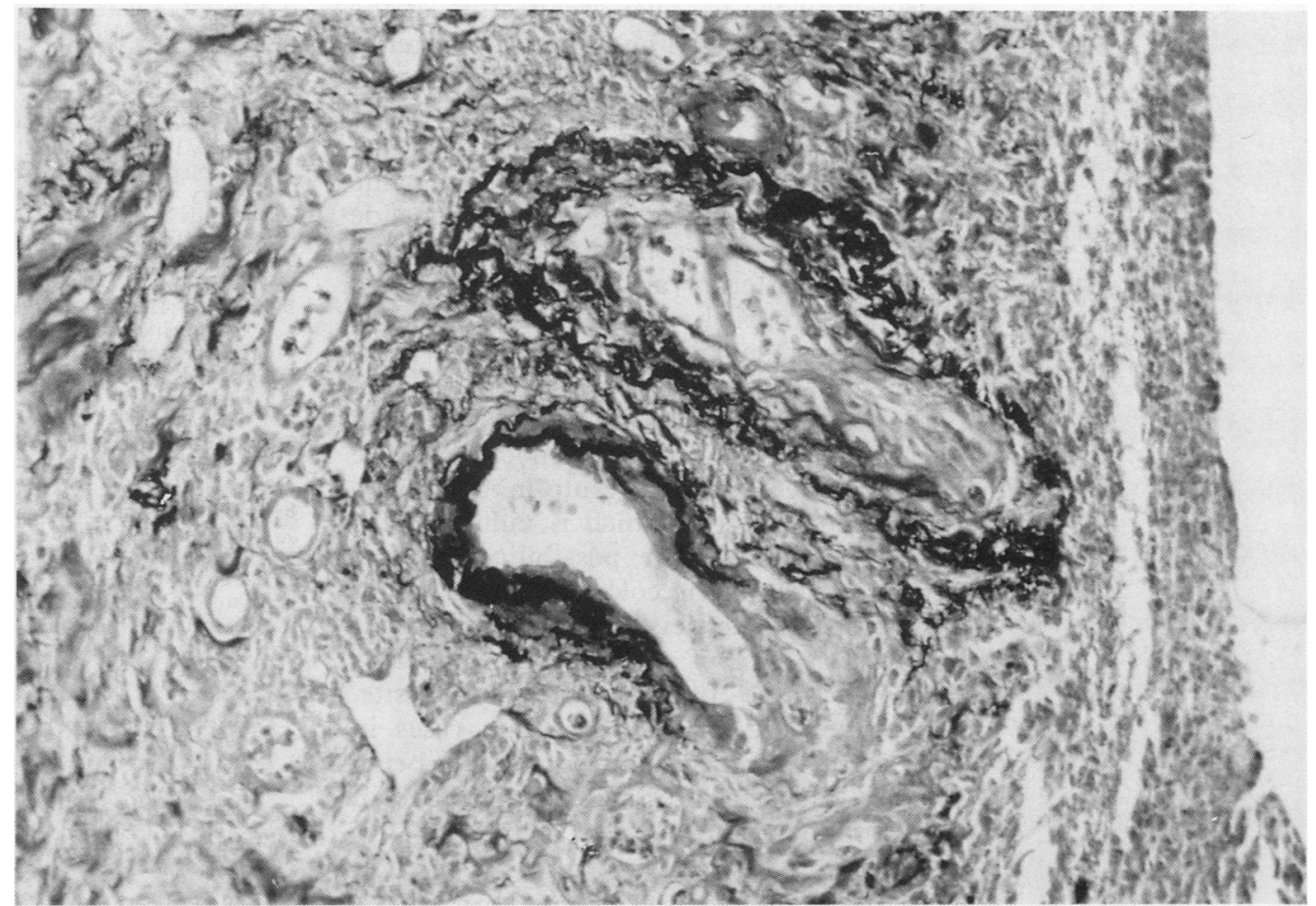

formation is not known, and as a cause of haematemesis it can be easily overlooked. ${ }^{8}$ It is probably an unrecognised rather than a rare cause of massive gastric bleeding ${ }^{1}$ and is much more common than reports indicate. ${ }^{9}$ Similarly, it has been suggested that cases in the colon may have generally gone unrecognised and are therefore not as rare as previously suggested. ${ }^{4}$

The cases we report confirm the belief that haemorrhage from a Dieulafoy type ulcer is becoming increasingly recognised as a specific cause of lower gastrointestinal bleeding. In reporting these cases we draw attention to this vascular malformation which should be considered when dealing with specimens resected for massive lower gastrointestinal haemorrhage or at necropsy. Indeed, it is not unusual for the diagnosis to be made at necropsy. ${ }^{1}$ Case 4 supports the theory that this vascular malformation can easily remain unrecognised and that the prevalence of such large calibre vessels can only be established by further evaluation of specimens obtained at colonic resection.

When dealing with cases of gastrointestinal bleeding, however, other specific vascular anomalies also need to be considered. These are rarely found in the gastrointestinal tract, but when present they are frequently a source of either acute and massive, or chronic, occult haemorrhage, and may be difficult to diagnose. ${ }^{10}$ The commonest of these are arteriovenous malformations (angiodysplasia, vascular ectasia) which are recognised most often on the right side of the colon in elderly patients. These lesions consist of irregularly shaped clusters of arteriolar, venular, and capillary vessels located in the mucosa and submucosa of the intestine. These are thought to result from increased pressure within the vessels due to chronic intermittent intraluminal pressure, causing obstruction of submucosal veins as they pierce the muscle layer of the bowel. ${ }^{11}$ Diagnosis is by colonoscopy or by angiography where there is the typical "coral reef" appearance, although biopsy is the only way to determine the exact nature of these lesions. ${ }^{12}$

The increased use of colonoscopy and selective visceral angiography have emphasised the extent to which vascular anomalies may be responsible for gastrointestinal haemorrhage, and have helped in making a firm diagnosis of such conditions as telangiectasia and diffuse cavernous haemangioma. However, gastrointestinal vascular anomalies such as telangiectasia may also be part of a more generalised disease, such as Osler-Weber-Rendu disease (hereditary haemorrhagic telangiectasia), Turner's syndrome, systemic sclerosis, or Raynaud's sclerodactyly. A careful personal and family history and general physical examination of the patient may therefore provide useful clues as to the likely nature of the vascular lesion. ${ }^{10}$

It seems reasonable to assume that Dieulafoy's vascular malformation may occur anywhere throughout the gastrointestinal tract. As well as the originally described site (the stomach), cases have also been reported in the lip (three cases), ${ }^{13}$ duodenum (one case), ${ }^{2}$ and jejunum (two cases). ${ }^{3}$ Within the large bowel five of the six reported cases occurred in either the caecum or ascending colon. We report four more cases occurring within the caecum.

Why should cases be localised to this area? Nearly 80 per cent of all gastric cases occur in a particular location (within $6 \mathrm{~cm}$ of the gastrooesophageal junction on the lesser curvature). The predilection for this location can be 
explained by the vascular architecture of the gastric blood supply. The submucosal arteries in the region of the lesser curvature do not arise from an extensive plexus of large vessels in the submucosa as is the case in the rest of the stomach. Instead they arise directly from the arterial chain along the lesser curvature outside the stomach. ${ }^{8}$ Under normal circumstances submucosal arteries are connected to the muscularis propria by Wanke's musculoelastic mantle. In Dieulafoy's malformation these arteries are also connected by a similar mantle to the muscularis mucosae and the thinned mucosa is permeated by smooth muscle bundles. These factors result in a circumscribed mucosal spot which is vulnerable to injury. ${ }^{9}$ This raises the possibility that the caecum and ascending colon may be similarly predisposed to the development of this malformation as $90 \%$ of all large intestinal cases (including these four) occur at this site. Alternatively, it may indicate that cases in other sites have gone unnoticed, perhaps being classified as gastrointestinal haemorrhage of undetermined origin.

We thank Professor OFW James, Mr CW Venables, $\mathrm{Mr}$ G Proud, Dr DN Bateman for allowing us to repeat these Mr G Proud, Dr DN Bateman for allowing us to repeat these
cases, Mrs Lesley Parker for typing the manuscript, and $\mathrm{Mr}$ cases, Mrs Lesley Parker for typing the marsh for producing the photographs.
Colin Mar.
1 Juler GL, Labitzke HG, Lamb R, Allen R. The pathogenesis of Dieulafoy's gastric erosion. Am J Gastroentero 1984;79:195-200.

2 Goldenberg SP, De Luca VA Jr, Marignani P. Endoscopic treatment of Dieulafoy's lesion of the duodenum. Am J Gastroenterol 1990;85:452-4.

3 Matuchansky C, Babin P, Abadie JC, Payen J, Gasquet C Barbier J. Jejunal bleeding from a solitary large mucosal artery. Gastroenterology 1978;75:110-3.

4 Richards WO, Grove-Mahoney D, Williams LF. Haemorrhage from a Dieulafoy type ulcer of the colon: A new cause of lower gastrointestinal bleeding. Am Surg 1988 54:121-4.

5 Barbier P, Luder P, Triller J, Ruchti Ch, Hassler H, Stafford A. Colonic haemorrhage from a solitary minute ulcerreport of three cases. Gastroenterology 1985;88:1065-8.

6 Schmid KW, Pointner R, Feichtinger J. Exulceratio simplex Dieulafoy of the colon - a case report. Endoscopy 1988;20:88-9.

7 Ma CK, Padda H, Pace EH, Szilagyi E. Submucosal arterial malformation of the colon with massive haemorragereport of a case. Dis Colon Rectum 1989;32:149-52.

8 Veldhuyzen van Zanten SJ, Bartelsman JF, Schipper ME Tytgat GN. Recurrent massive haematemesis from Dieulafoy vascular malformations-a review of 101 cases. Gut 1986;27:213-22

9 Miko TL, Thomazy VA. The calibre persistent artery of the stomach: A unifying approach to gastric aneurysm Dieulafoy's lesion, and submucosal arterial malformation Hum Pathol 1988;19:914-21.

10 Camilleri M, Chadwick VS, Hodgson HJ. Vascular anomalies of the gastrointestinal tract. Hepatogastroenterology 1984;31:149-53.

11 Boley SJ, Sammartano R, Adams A, Diabiase A, Kleinhaus S, Sprayregen $S$. On the nature and aetiology of vascular ectasias of the colon. Gastroenterology 1977;72:650-60.

12 Roberts PL, Schoetz DJ, Coller JA. Vascular ectasiadiagnosis and treatment by colonoscopy. Am Surg 1988; 54:56-9.

13 Miko T, Adler P, Endes P. Simulated cancer of the lower lip attributed to a "calibre persistent" artery. J Oral Pathol 1980;9:137-44. 